\title{
ZENER-STROH CRACK PROBLEM IN A FINITE PLATE
}

\section{Yizhou Chen}

Division of Engineering Mechanics, Jiangsu University, Zhenjiang, Jiangsu, 212013 People's Republic of China., chens@ujs.edu.cn

\section{Recommended Citation}

Chen, Yizhou (2011) "ZENER-STROH CRACK PROBLEM IN A FINITE PLATE," Journal of Marine Science and Technology. Vol. 19: Iss. 2, Article 3.

DOI: 10.51400/2709-6998.2146

Available at: https://jmstt.ntou.edu.tw/journal/vol19/iss2/3

This Research Article is brought to you for free and open access by Journal of Marine Science and Technology. It has been accepted for inclusion in Journal of Marine Science and Technology by an authorized editor of Journal of Marine Science and Technology. 


\section{ZENER-STROH CRACK PROBLEM IN A FINITE PLATE}

\begin{abstract}
Key words: Zener-Stroh crack, initial stress state, stress intensity factor, variational principle.

ABSTRACT

In this paper, a Zener-Stroh crack problem in a finite plate is studied. By using the principle of superposition, the original problem is converted into a Zener-Stroh crack problem in an infinite plate and a usual Griffith crack problem in a finite plate. The former problem has a solution in a closed form. The latter problem can be solved by using EEVM (eigenfunction expansion variational method). Finally, numerical examples for evaluating the stress intensity factors at crack tips are presented.
\end{abstract}

Yizhou Chen*

\section{INTRODUCTION}

The initial stress problem has a long history in literature [8, 9]. When no tractions are applied on the boundary of an elastic medium, the stresses may exist in the medium. This is the initial stress problem. The initial stress problem can be interpreted as some accumulation of dislocations in the elastic body. If the elastic body contains a crack, the initial stress problem becomes the Zener-Stroh crack problem. In the ZenerStroh crack, one must assume an initial additional displacement jump (abbreviated IAD), which is a counterpart of tractions in the Griffith crack. Therefore, once the IAD is given beforehand, a Zener-Stroh crack problem will be formulated. Many researchers investigated the Zener-Stroh crack from a viewpoint of materials science $[6,11,12]$. They also consider the Zener-Stroh crack as an accumulation of dislocations.

Some Zener-Stroh crack problems were solved [2, 4, 5]. An interfacial Zener-Stroh crack was studied, and difference of governing equations for the Griffith crack and the Zener-Stroh crack was discussed in detail [4]. A Zener-Stroh crack in antiplane elasticity was investigated [5]. Multiple Zener-Stroh crack problem was solved using the singular integral equation [2].

A general formulation for solutions of integral equations in

Paper submitted 12/09/09; revised 01/26/10; accepted 02/05/10. Author for correspondence: Yizhou Chen (e-mail: chens@ujs.edu.cn).

*Division of Engineering Mechanics, Jiangsu University, Zhenjiang, Jiangsu, 212013 People's Republic of China. elasticity was suggested [7]. Particularly, a line crack problem with constant loading on the crack face was solved in a closed form by using hypersingualr integral equation.

In this paper, Zener-Stroh crack problem in a finite plate is studied. By using the principle of superposition, the original problem is converted into a Zener-Stroh crack problem in an infinite plate and a usual Griffith crack problem in a finite plate. The former problem has a solution in a closed form. The latter problem can be solved by using EEVM (eigenfunction expansion variational method) [1]. Finally, numerical examples for evaluating the stress intensity factors (SIFs) at crack tips are presented.

\section{ANALYSIS FOR A ZENER-STROH CRACK IN A FINITE PLATE}

We first discuss the single Zener-Stroh crack problem in an infinite plate (Fig. 1). It is assumed that there is a block (Fig. 1(a)). A thinner layer of materials " $b_{1} c_{1} c_{2} b_{2}$ " is removed from the block, and two flanges " $\mathrm{b}_{1} \mathrm{c}_{1}$ " and " $\mathrm{b}_{2} \mathrm{c}_{2}$ " are exposed. After welding the flange " $\mathrm{b}_{1} \mathrm{c}_{1}$ " to " $\mathrm{b}_{2} \mathrm{c}_{2}$ ", a Zener-Stroh crack "AB" is thus formed (Fig. 1(a)). The amount of the displacement " $\tilde{\mathrm{v}}$ " in Fig. 1 (a), which is the thickness of the thinner layer " $b_{1} c_{1} c_{2} b_{2}$ " is called the initial additional displacement jump (IAD), which is in $y$-direction in the present case. In this case, in the left and right crack tips the first mode stress intensity factors exists. Similarly, if the IAD is in $x$-direction the second mode fracture encounters.

In the formulation of boundary value problem for a ZenerStroh crack (Fig. 1(b)), the dislocation distribution function $\mathrm{g}^{\prime}(\mathrm{t})$ is defined by $[3,10]$

$g^{\prime}(t)=-\frac{2 G i}{\kappa+1} \frac{d}{d t}\left[(u(t)+i v(t))^{+}-(u(t)+i v(t))^{-}\right],(|t|<a)$

where $(\mathrm{u}(\mathrm{t})+\mathrm{iv}(\mathrm{t}))^{+},\left((\mathrm{u}(\mathrm{t})+\mathrm{iv}(\mathrm{t}))^{-}\right)(\mathrm{u}$ in $x$-direction, $\mathrm{v}$ in $y$-direction) denotes the displacement at upper (lower) crack face, respectively, $G$ the shear modulus of elasticity, $\kappa=(3-v) /$ $(1+v)$ in plane stress case, $\kappa=3-4 v$ in plane strain case, and $v$ the Poisson's ratio. Since the influence of the function $g^{\prime}(t)$ at any point " $z$ " can be evaluated (Fig. 1(c)), the traction free condition on the crack faces will lead to the following singular integral equation $[3,10]$ 


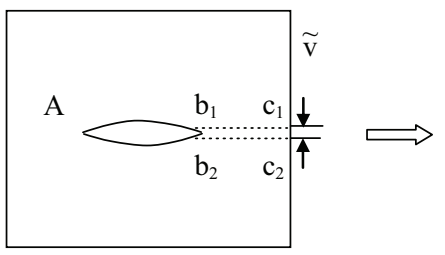

Remove materials

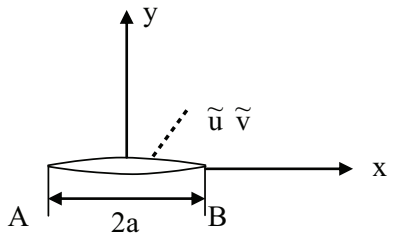

(b)

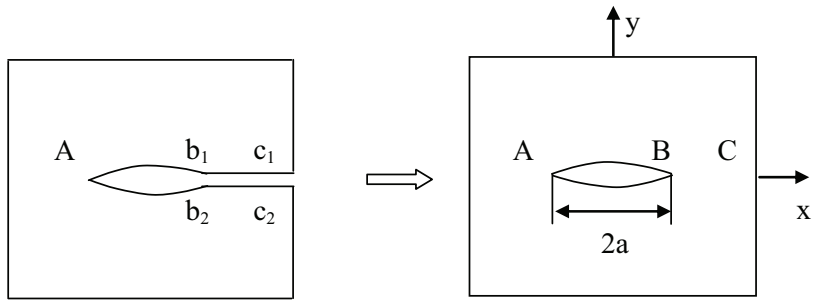

Weld the flanges $\mathrm{b}_{1} \mathrm{c}_{1}$ and $\mathrm{b}_{2} \mathrm{c}_{2}$

(a)

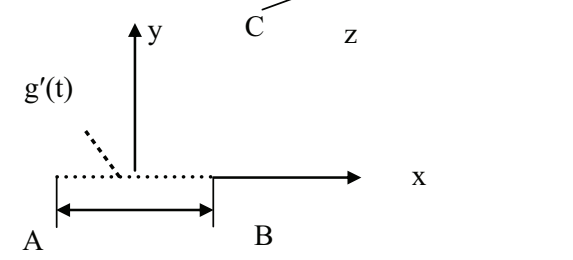

(c)

Fig. 1. (a) Formulation of the Zener-Stroh crack, (b) a Zener-Stroh crack in an infinite plate, (c) dislocation distribution g'(t) placed along the interval $(-\mathbf{a}, \mathbf{a})$.

$$
\int_{-a}^{a} \frac{g^{\prime}(t) d t}{t-t_{o}} d t=0,\left(\left|t_{o}\right|<a\right),
$$

In addition, it is assumed that the amount of $\operatorname{IAD}$ is $(\tilde{\mathrm{u}}, \tilde{\mathrm{v}})$. From this condition and Eq. (1) we have

$$
\int_{-a}^{a} g^{\prime}(t) d t=\frac{2 G}{\kappa+1}(\tilde{v}-i \tilde{u})
$$

In Eq. (3), ( $\tilde{\mathrm{u}}, \tilde{\mathrm{v}})$ is given beforehand, which represents the generalized loading in the Zener-Stroh crack problem. From Eqs. (2) and (3) we can get a solution as follows [3]

$$
\mathrm{g}^{\prime}(\mathrm{t})=\frac{2 \mathrm{G}}{\pi(\kappa+1)} \frac{(\tilde{\mathrm{v}}-\mathrm{i} \tilde{\mathrm{u}})}{\sqrt{\mathrm{a}^{2}-\mathrm{t}^{2}}},(|\mathrm{t}|<\mathrm{a})
$$

The SIFs at the left and right crack tips " $A$ " and " $B$ " in Fig. 1(b) can be defined by $[3,10]$

$$
\begin{aligned}
& \left(\mathrm{K}_{1}-\mathrm{iK}_{2}\right)_{\mathrm{A}}=(2 \pi)^{1 / 2} \operatorname{Lim}_{\mathrm{t} \rightarrow-\mathrm{a}} \sqrt{|\mathrm{t}+\mathrm{a}|} \mathrm{g}^{\prime}(\mathrm{t}), \\
& \left(\mathrm{K}_{1}-\mathrm{iK}_{2}\right)_{\mathrm{B}}=-(2 \pi)^{1 / 2} \operatorname{Lim}_{\mathrm{t} \rightarrow \mathrm{a}} \sqrt{|\mathrm{t}-\mathrm{a}|} \mathrm{g}^{\prime}(\mathrm{t})
\end{aligned}
$$

Substituting Eq. (4) into (5) yields

$$
\left(\mathrm{K}_{1}-\mathrm{iK}_{2}\right)_{\mathrm{A}}=-\left(\mathrm{K}_{1}-\mathrm{iK}_{2}\right)_{\mathrm{B}}=\frac{2 \mathrm{G}}{(\kappa+1)} \frac{(\tilde{\mathrm{v}}-\mathrm{i} \tilde{\mathrm{u}})}{\sqrt{\pi \mathrm{a}}}
$$

The solution for a Zener-Stroh crack in a finite plate is introduced below (Fig. 2). It is assumed that the crack in a finite plate undergoes an IAD with the amount $\tilde{\mathrm{V}}$, and the crack faces and the outer boundary are of traction free. The problem is denoted by the problem " $\mathrm{O}$ " hereafter. The original problem "O" can be considered as a superposition of the problems "P" and "Q" (Fig. 2). In the problem "P", the crack in an infinite plate undergoes an IAD with the amount $\tilde{\mathrm{V}}$. Therefore, from Eq. (6) the SIFs at the crack tip "A" and "B" can be expressed as

$$
\left(\mathrm{K}_{1}\right)_{\mathrm{A}}=-\left(\mathrm{K}_{1}\right)_{\mathrm{B}}=\frac{2 \mathrm{G}}{(\kappa+1)} \frac{\tilde{\mathrm{v}}}{\sqrt{\pi \mathrm{a}}}
$$

Obviously, in the problem "Q" the applied boundary tractions are the same in magnitude and opposite in direction with those in the problem "P" (Fig. 2). If the dislocation distribution $\mathrm{g}^{\prime}(\mathrm{t})$ is applied along the interval $(-\mathrm{a}$, a) ( Fig. 1(c)), the traction $\mathrm{N}+\mathrm{iT}$ at the point " $\mathrm{z}$ " on the segment "CD" can be expressed as [3]

$$
\begin{aligned}
\mathrm{N}+\mathrm{iT}= & \frac{1}{2 \pi} \int_{-\mathrm{a}}^{\mathrm{a}}\left(\frac{1}{\mathrm{t}-\mathrm{z}}+\exp (-2 i \beta) \frac{1}{\mathrm{t}-\overline{\mathrm{z}}}\right) \mathrm{g}^{\prime}(\mathrm{t}) \mathrm{dt} \\
& +\frac{1}{2 \pi} \int_{-\mathrm{a}}^{\mathrm{a}}\left(\frac{1}{\mathrm{t}-\overline{\mathrm{z}}}-\exp (-2 \mathrm{i} \beta) \frac{\mathrm{t}-\mathrm{z}}{(\mathrm{t}-\overline{\mathrm{z}})^{2}}\right) \overline{\mathrm{g}^{\prime}(\mathrm{t})} \mathrm{dt}
\end{aligned}
$$

where " $\beta$ " is the inclined angle of the segment "CD".

After using the following steps: (a) substituting $g^{\prime}(t)=$ 


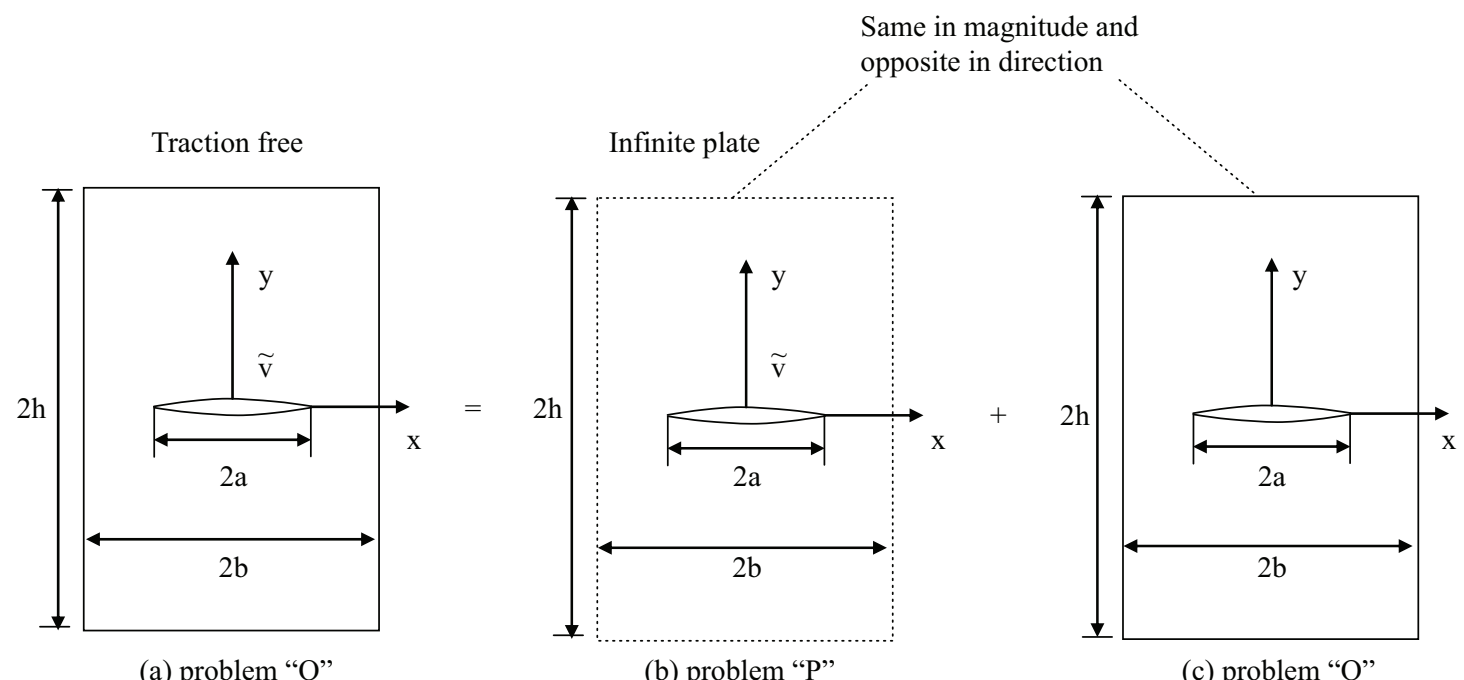

Fig. 2. Superposition principle in the solution: (a) problem “O”, (b) problem "P”, (c) problem "Q".

$2 \mathrm{G} \tilde{\mathrm{v}} /\left[\pi(\kappa+1) \sqrt{\mathrm{a}^{2}-\mathrm{t}^{2}}\right]$ into Eq. (8), (b) taking a point at the outer boundary as the point " $z$ " in Eq. (8), the boundary tractions on the outer boundary of the cracked plate in the problems " $P$ " and " $Q$ " can be easily be found.

The complex variable function method is used to solve the problem "Q" [9]. Fundamental of this method is introduced below. In the method, the stresses $\left(\sigma_{\mathrm{x}}, \sigma_{\mathrm{v}}, \sigma_{\mathrm{xv}}\right)$, the resultant forces $(\mathrm{X}, \mathrm{Y})$ and the displacements $(\mathrm{u}, \mathrm{v})$ are expressed in terms of complex potentials $\phi(\mathrm{z})$ and $\psi(\mathrm{z})$ or complex potentials $\phi(z)$ and $\omega(z)$ such that

$$
\begin{gathered}
\sigma_{x}+\sigma_{y}=4 \operatorname{Re} \Phi(z) \\
\sigma_{y}-i \sigma_{x y}=2 \operatorname{Re} \Phi(z)+z \overline{\Phi^{\prime}(z)}+\overline{\Psi(z)} \\
=\Phi(z)+(z-\bar{z}) \overline{\Phi^{\prime}(z)}+\Omega(\bar{z}) \\
f=-Y+i X=\phi(z)+z \overline{\phi^{\prime}(z)}+\overline{\psi(z)} \\
=\phi(z)+(z-\bar{z}) \overline{\phi^{\prime}(z)}+\omega(\bar{z}) \\
2 G(u+i v)=\kappa \phi(z)-z \overline{\phi^{\prime}(z)}-\overline{\psi(z)} \\
=\kappa \phi(z)-(z-\bar{z}) \overline{\phi^{\prime}(z)}-\omega(\bar{z})
\end{gathered}
$$

In Eqs. (9)-(11), the functions $\omega(\mathrm{z}), \Phi(\mathrm{z}), \Psi(\mathrm{z})$ and $\Omega(\mathrm{z})$ are defined $[3,9]$

$$
\begin{aligned}
& \omega(\mathrm{z})=\mathrm{z} \bar{\phi}^{\prime}(\mathrm{z})+\bar{\psi}(\mathrm{z}), \Phi(\mathrm{z})=\phi^{\prime}(\mathrm{z}) \\
& \Psi(\mathrm{z})=\psi^{\prime}(\mathrm{z}), \Omega(\mathrm{z})=\omega^{\prime}(\mathrm{z})
\end{aligned}
$$

Note that, in Eq. (12) the function $\bar{\psi}(\mathrm{z})$ is an analytic function which is defined by $\bar{\psi}(\mathrm{z})=\overline{\psi(\overline{\mathrm{z}})}$.

In the mentioned Zener-Stroh crack problem with IAD " $\tilde{V}$ ", the elastic fields in the problem "O", "P' and "Q" have the following properties

$$
\begin{aligned}
u(x, y) & =u(-x, y)=u(x,-y)=u(-x,-y) \\
v(x, y) & =-v(-x, y)=-v(x,-y) \\
& =v(-x,-y) \\
\sigma_{x}(x, y) & =-\sigma_{x}(-x, y)=\sigma_{x}(x,-y) \\
& =-\sigma_{x}(-x,-y) \\
\sigma_{y}(x, y) & =-\sigma_{y}(-x, y)=\sigma_{y}(x,-y) \\
& =-\sigma_{y}(-x,-y) \\
\sigma_{x y}(x, y) & =\sigma_{x y}(-x, y)=-\sigma_{x y}(x,-y) \\
& =-\sigma_{x y}(-x,-y)
\end{aligned}
$$

From the conditions shown by Eq. (13), the appropriate complex potentials for $\phi(z)$ and $\omega(\mathrm{z})$ should take the form [1]

$$
\phi(\mathrm{z})=\sum_{\mathrm{k}=1}^{\mathrm{M}} \mathrm{E}_{\mathrm{k}} \sqrt{\mathrm{z}^{2}-\mathrm{a}^{2}} \mathrm{z}^{2 \mathrm{k}-1}+\sum_{\mathrm{k}=1}^{\mathrm{M}} \mathrm{F}_{\mathrm{k}} \mathrm{z}^{2 \mathrm{k}-2}\left(\mathrm{E}_{\mathrm{k}}, \mathrm{F}_{\mathrm{k}}-\text { real }\right)
$$

$\omega(z)=\sum_{k=1}^{M} E_{k} \sqrt{z^{2}-a^{2}} z^{2 k-1}-\sum_{k=1}^{M} F_{k} z^{2 k-2}\left(E_{k}, F_{k}-\right.$ real $)$ 
Table 1. Non-dimensional stress intensity factors $F(a / b, h / b)$ and $G(a / R)$ (see Figs. 2 and 3, and Eqs. (16) and (17)). For the finite rectangular pate $\mathrm{F}(\mathrm{a} / \mathrm{b}, \mathrm{h} / \mathrm{b})$

\begin{tabular}{ccccccccc}
\hline $\mathrm{a} / \mathrm{b}=$ & 0.1 & 0.2 & 0.3 & 0.4 & 0.5 & 0.6 & 0.7 & 0.8 \\
$\mathrm{~h} / \mathrm{b}=0.4$ & 0.9355 & 0.7979 & 0.6634 & 0.5580 & 0.4834 & 0.4365 & 0.4097 & 0.3770 \\
$\mathrm{~h} / \mathrm{b}=0.6$ & 0.9711 & 0.8987 & 0.8110 & 0.7284 & 0.6574 & 0.5929 & 0.5218 & 0.4279 \\
$\mathrm{~h} / \mathrm{b}=0.8$ & 0.9839 & 0.9399 & 0.8779 & 0.8069 & 0.7303 & 0.6466 & 0.5509 & 0.4376 \\
$\mathrm{~h} / \mathrm{b}=1.0$ & 0.9880 & 0.9535 & 0.9004 & 0.8325 & 0.7525 & 0.6612 & 0.5577 & 0.4395 \\
$\mathrm{~h} / \mathrm{b}=1.5$ & 0.9894 & 0.9583 & 0.9082 & 0.8412 & 0.7596 & 0.6656 & 0.5598 & 0.4397 \\
$\mathrm{~h} / \mathrm{b}=2.0$ & 0.9895 & 0.9584 & 0.9083 & 0.8413 & 0.7597 & 0.6663 & 0.5611 & 0.4428 \\
\hline For the cracked circular plate G(a/R) & 0.1 & 0.2 & 0.3 & 0.4 & 0.5 & 0.6 & 0.7 \\
\hline $\mathrm{a} / \mathrm{R}=$ & 0.9852 & 0.9433 & 0.8804 & 0.8034 & 0.7177 & 0.6259 & 0.5279 & 0.4197 \\
\hline
\end{tabular}

The EEVM (eigenfunction expansion variational method) is used to evaluate the SIFs at crack tips [1]. The SIF at the right crack tip " $\mathrm{B}$ " can be evaluated by

$$
\begin{aligned}
& \left(\mathrm{K}_{1}\right)_{\mathrm{B}}=\operatorname{Lim}_{\mathrm{z} \rightarrow \mathrm{a}} 2 \sqrt{2 \pi(\mathrm{z}-\mathrm{a})} \phi^{\prime}(\mathrm{z})=2 \sqrt{\frac{\pi}{\mathrm{a}}} \sum_{\mathrm{k}=1}^{\mathrm{M}} \mathrm{E}_{\mathrm{k}} \mathrm{a}^{2 \mathrm{k}} \\
& \left(\mathrm{K}_{1}\right)_{\mathrm{A}}=-\left(\mathrm{K}_{1}\right)_{\mathrm{B}}
\end{aligned}
$$

Since the SIFs at the crack tips in the problems "P" and "Q" can be evaluated by Eqs. (7) and (15), respectively, the SIFs at the crack tips in the original problem "O" can be evaluated immediately using the principle of superposition.

For the rectangular cracked plate, in the case of using $\mathrm{M}=$ 18 in Eqs. (14) and (15), the calculated SIFs at crack tips "A" and "B" are expressed as

$$
\left(\mathrm{K}_{1}\right)_{\mathrm{A}}=-\left(\mathrm{K}_{1}\right)_{\mathrm{B}}=\frac{2 \mathrm{G}}{(\kappa+1)} \frac{\tilde{\mathrm{v}}}{\sqrt{\pi \mathrm{a}}} \mathrm{F}(\mathrm{a} / \mathrm{b}, \mathrm{h} / \mathrm{b})
$$

The calculated values for $\mathrm{F}(\mathrm{a} / \mathrm{b}, \mathrm{h} / \mathrm{b})$ are listed in Table 1 . The adoption of $\mathrm{M}=18$ is simply based on experience.

From Table 1 we see that the influence of boundary condition to the $\mathrm{F}(\mathrm{a} / \mathrm{b}, \mathrm{h} / \mathrm{b})$ values is significant. For example, in the case of infinite plate, or $\mathrm{a} / \mathrm{b} \approx 0$, we have $\mathrm{F}(\mathrm{a} / \mathrm{b}, \mathrm{h} / \mathrm{b}) \approx 1$. In addition, if $\mathrm{a} / \mathrm{b}=0.1$ and $\mathrm{h} / \mathrm{b}=2.0$, we have $\mathrm{F}(\mathrm{a} / \mathrm{b}, \mathrm{h} / \mathrm{b})=0.9895$. However, if $\mathrm{a} / \mathrm{b}=0.8$ and $\mathrm{h} / \mathrm{b}=2.0$, we have $\mathrm{F}(\mathrm{a} / \mathrm{b}, \mathrm{h} / \mathrm{b})=$ 0.4428 . In the Zener-Stroh crack, if the ratio $a / b$ is large, the $\mathrm{F}(\mathrm{a} / \mathrm{b}, \mathrm{h} / \mathrm{b})$ value becomes small. This situation is different from the case of a Griffith crack.

The computed results for SIFs in Zener-Stroh crack are very few. However, We can make an approximate comparison. In this paper, when $\mathrm{a} / \mathrm{b}=0.2$ and $\mathrm{h} / \mathrm{b}=2.0$, we have non-dimensional SIF values as follows: $\mathrm{F}=0.9584$ (at the left crack tip) and $\mathrm{F}=-0.9584$ (at the right crack tip). In the meantime, for two Zener-Stroh cracks in series with a spacing $d=a$ (here "a" is half crack length) [2]. we have non-dimensional SIFs as fol-

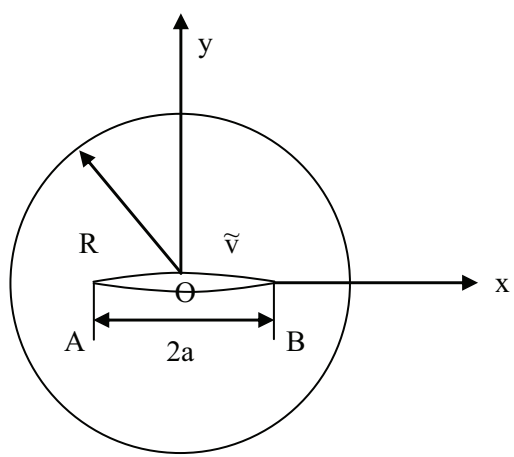

Fig. 3. A Zener-Stroh crack in a circular plate.

lows: $F=0.6724$ (at the left crack tip) and $F=-1.5034$ (at the right crack tip). From the mentioned results we see that the interaction of Zener-Stroh crack with boundaries or with other crack is a complicated problem.

Similarly, for a circular plate with a central crack (Fig. 3), in the case of using $M=18$ in Eqs. (7) and (15), the calculated SIFs at crack tips "A" and "B" are expressed as

$$
\left(\mathrm{K}_{1}\right)_{\mathrm{A}}=-\left(\mathrm{K}_{1}\right)_{\mathrm{B}}=\frac{2 \mathrm{G}}{(\kappa+1)} \frac{\tilde{\mathrm{v}}}{\sqrt{\pi \mathrm{a}}} \mathrm{G}(\mathrm{a} / \mathrm{R})
$$

The calculated values for $\mathrm{G}(\mathrm{a} / \mathrm{R})$ are also listed in Table 1.

\section{CONCLUSIONS}

An elastic body may not have loading applied on the body, but has some accumulation of dislocation in the body. This will become a wide range problem in elasticity, or so-called initial stress problem. This study is devoted to a particular initial stress problem arising from the Zener-Stroh crack problem. It is worthy to mention some particular feature in the study. For example, for the single Zener-Stroh crack case, if the SIF at the left crack tip is positive, then the SIF at the right crack tip must be negative. 


\section{REFERENCES}

1. Chen, Y. Z., "An investigation of the stress intensity factor for a finite internally cracked plate by using variational method," Engineering Fracture Mechanics, Vol. 17, pp. 387-394 (1983).

2. Chen, Y. Z., "Multiple Zener-Stroh crack problem in an infinite plate," Acta Mechanica, Vol. 170, pp. 11-23 (2004).

3. Chen, Y. Z., Hasebe, N., and Lee, K. Y., Multiple Crack Problems in Elasticity, WIT Press, Southampton (2003).

4. Fan, H., "Interfacial Zener-Stroh crack," Journal of Applied Mechanics, Vol. 61, pp. 829-834 (1994).

5. Fan, H. and Xiao, Z. M., "A Zener-Stroh crak near an interface," International Journal of Solids and Structure, Vol. 34, pp. 2829-2842 (1997).

6. Hirth, J. P. and Lothe, J., Theory of Dislocations, John Wiley, New York (1982).
7. Hong, H. K. and Chen, J. T., "Derivations of integral equations of elasticity," ASCE Journal of Engineering Mechanics, Vol. 114, pp. 1028-1044 (1988).

8. Love, A. E. H., A Treatise on the Mathematical Theory of Elasticity, Oxford, London (1944).

9. Muskhelishvili, N. I., Some Basic Problems of the Mathematical Theory of Elasticity, Noordhoff, Netherlands (1953).

10. Panasyuk, V. V., Savruk, M. P., and Datsyshyn, A. P., "A general method of solution of two-dimensional problems in the theory of cracks," Engineering Fracture Mechanics, Vol. 9, pp. 481-497 (1977).

11. Stroh, A. N., "The formulation of cracks as a result of plastic flow I," Proceedings of the Royal Society London, Vol. A223, pp. $404-414$ (1954).

12. Weertman, J., "Zener-Stroh Crack, Zener-Hollomon Parameter, and other topics," Journal of Applied Physics, Vol. 60, pp. 1877-1887 (1996). 